\title{
A Cartografia de Síntese como Instrumento para a Avaliação do Potencial da Dinâmica Erosiva Linear em Domínio de Cuesta
}

\author{
Synthesis Cartography as Instrument for Evaluating Potential of Linear Erosive Dynamics \\ in Cuesta Domain
}

Estêvão Botura Stefanuto ${ }^{1}$, Cenira Maria Lupinacci ${ }^{2}$

1 Universidade Estadual Paulista - UNESP, Programa de Pós-Graduação em Geografia, Rio Claro, Brasil. estevao1508@hotmail.com.

ORCID: https://orcid.org/0000-0001-6580-2563

2 Universidade Estadual Paulista - UNESP, Departamento de Geografia e Planejamento Ambiental - DGPA, Rio Claro, Brasil. cenira.lupinacci@unesp.br.

ORCID: https://orcid.org/0000-0002-4732-1421

Resumo: A erosão do solo pela água é estimada em um custo anual de bilhões de dólares para o PIB global. Para estudar essa problemática, considera-se que avaliar a disposição espacial dos fenômenos erosivos, assim como a interação das variáveis que influenciam sua dinâmica, constitui-se em uma prerrogativa essencial. Neste sentido, o objetivo deste artigo é apresentar procedimentos metodológicos adotados para o desenvolvimento de cartas de síntese a fim de identificar o potencial dos terrenos ao avanço da erosão linear. As variáveis utilizadas para analisar o potencial erosivo foram a morfometria do relevo, as características físicas dos solos e o uso da terra. Foram utilizados princípios da álgebra de mapas, com destaque para a sobreposição ponderada das variáveis, partindo de influências diferentes para cada uma destas e de técnicas distintas para o estabelecimento de pesos para as classes de cada variável. Os documentos cartográficos criados foram avaliados a partir da comparação destes com dados experimentais de campo e de mapeamentos das feições lineares. Constatou-se que as melhores respostas ocorreram quando se considerou influência equânime para as variáveis físicas e de uso da terra, demonstrando que as feições erosivas são fruto da interação entre a ação humana e as características naturais do terreno. Foi possível também concluir que os procedimentos técnicos que permitem obter bons resultados para avaliar o potencial ao desenvolvimento de voçorocas, não respondem adequadamente para sulcos e ravinas, havendo necessidade de adaptações. Considera-se que as cartas elaboradas, assim como os procedimentos metodológicos desenvolvidos, possuem sustentação para a análise da dinâmica erosiva linear em setores de Cuesta, uma vez que foi possível obter produtos cartográficos que apresentaram boa correspondência espacial com as feições erosivas registradas no terreno.

Palavras-chave: Cartografia. Erosão. Diagnóstico erosivo. Evolução erosiva.

\begin{abstract}
Soil erosion by water is estimated at an annual cost of billions of dollars to global GDP. To study this problem, we consider that evaluating the spatial disposition of erosive phenomena, as well as the interaction of variables that influence their dynamics, constitutes an essential prerogative. Thus, the aim of this article is to present methodological procedures adopted for the development of synthesis maps in order to identify the potential of the land to advance linear erosion. The variables used to analyze the erosive potential were relief morphometry, soil physical characteristics and land use. Principles of map algebra were used, with emphasis on the weighted overlay of the variables, starting from different influences for each of these and different techniques for the establishment of weights for the classes of each variable. The cartographic documents created were evaluated from the comparison of these with experimental field data and mapping of linear features. It was found that the best answers occurred when an equitable influence was considered for the physical and land use variables, demonstrating that erosive features are the result of the interaction between human action and the natural characteristics of the terrain. It was also possible to conclude that the technical procedures that allow us to obtain good results to assess the potential for the development of gullies, don't respond adequately to rill erosion and ravines, and there is a need for adaptations. It's considered that the maps elaborated, as well as the methodological procedures developed, support for the analysis of linear erosive dynamics in Cuesta sectors, for it was possible to obtain cartographic products that presented good spatial correspondence with the erosive features recorded in the field.
\end{abstract}

Keywords: Cartography. Erosion. Erosive diagnosis. Erosive evolution. 


\section{INTRODUÇÃO}

A erosão dos solos constitui-se em uma problemática global, a qual atinge diferentes esferas do cotidiano das mais diversas sociedades do mundo, sendo tal fato ratificado pela importância empregada na análise da temática por algumas agências como a Organização das Nações Unidas para a Alimentação e a Agricultura (FAO, 2015). A erosão do solo pela água, por exemplo, é estimada em um custo anual de US\$ 8 bilhões para o PIB global, se identificando, concomitantemente, uma redução da produção agroalimentar mundial na esfera de 33,7 milhões de toneladas (SARTORI et al., 2019). Neste cenário, o Brasil merece atenção, uma vez que figura entre os países que estão na segunda maior classe de terras com perda de produtividade (5.75-6.90\%) a nível global (SARTORI et al., 2019). Portanto, a busca por metodologias científicas que auxiliem na melhoria deste cenário faz-se de suma importância.

Neste sentido, diferentes estudos apontam que as propriedades físicas dos solos (MAFRA, 1999; FENDRICH et al., 1997; VAZ et al., 2011; BERTONI; LOMBARDI NETO, 2012; MATHIAS, 2016), a dinâmica dos fluxos superficiais (MAHMOODABADI; SAJJADI, 2016; AL-HAMDAN et al., 2013), a inclinação dos terrenos (SHEN et al., 2016; ZHANG et al., 2019) e o uso e ocupação da terra (NOUWAKPO et al., 2016; CHU et al., 2019; COUTO et al., 2019) constituem-se nos aspectos mais importantes para a avaliação da erosão.

Assim, reconhece-se a contribuição de cada uma das variáveis supracitadas para o desenvolvimento de processos erosivos, no entanto, em uma perspectiva de análises dos sistemas terrestre através dos princípios da complexidade (MURRAY et al., 2009), entende-se que as variáveis apresentadas interagem entre si e que desta interação se desenvolvem parte dos processos erosivos. Ainda, a partir da análise de tal interação, um conjunto de dados complexos pode ser identificado (CHRISTOFOLETTI, 1999; LIMBERGER, 2006, MURRAY et al., 2009), uma vez que os sistemas podem passar a emitir respostas não lineares, as quais são de difícil previsibilidade (MURRAY et al., 2009) e atuam no campo das incertezas (STEFANUTO et al., 2017). Neste sentido, a disposição espacial dos fenômenos é uma prerrogativa para o entendimento das variáveis que influenciam a dinâmica erosiva, sendo que as ferramentas dos Sistemas de Informação Geográfica - SIG apresentam um caminho analítico consolidado em diversas pesquisas (MATHIAS, 2016; ZANATTA, 2018; LIMA, PINTO, LANDIM, 2014), nas quais o grau de incerteza pode ser amenizado. Gholami et al. (2021), por exemplo, obtiveram bons resultados na formulação de um mapa com as taxas de erosão dos solos através de um compilado entre dados de campo coletados por pinos de erosão, combinação de variáveis através de SIG e tratamentos de dados por Redes Neurais Artificiais. Também Teng et al. (2016) elaboraram um modelo cartográfico sobre as perdas de solo por erosão hídrica na Austrália, através de produtos de sensoriamento remoto e dos parâmetros sugeridos pela Equação Universal de Perda de Solo Revisada (RUSLE). Ainda neste sentido, Prasuhn et al. (2013), através da aplicação da Equação Universal de Perda de Solo Modificada (MUSLE), também formularam mapas de potencial de risco a erosão para a Suíça, os quais subsidiaram o desenvolvimento de políticas públicas.

Considerando os diversos estudos apontados, avalia-se que a problemática da erosão pode ser estudada a partir do entendimento da relação entre diversos elementos do meio físico e antrópico que, ao interagirem, potencializam os processos erosivos. Dessa forma, a cartografia de síntese pode se constituir como uma ferramenta importante para tais estudos. Compreende-se a cartografia de síntese como tradicionalmente proposto por Claval e Wieber (1969, apud MARTINELLI, 2003) que enfatizam a busca pelas correlações, evidenciando que a cartografia de síntese pode permitir identificar as conexões entre fenômenos distintos. Sampaio (2012, p. 122) complementa essa noção ao afirmar que a cartografia de síntese pode "gerar uma nova informação capaz de fornecer uma visão diferenciada do conjunto de atributos envolvidos". Há diversas técnicas para a produção de mapas de síntese, sendo que, nos SIGs, a álgebra de mapas destaca-se pelas inúmeras possibilidades de combinação das variáveis (QUEIROZ FILHO, MARTINELLI, 2007). A álgebra de mapas permite manipular conjuntos de dados raster com expressões algébricas relativamente simples, assim como, na visão de Mennis (2010), combinar essas expressões em programas que modelam fenômenos geográficos mais complexos.

Portanto, o objetivo deste artigo foi desenvolver uma cartografia de síntese a fim de avaliar o potencial dos terrenos ao avanço da erosão linear, utilizando dados da morfometria do relevo, das características físicas 
dos solos e do uso da terra. Os documentos cartográficos criados a partir dessa cartografia de síntese foram avaliados por meio da comparação com dados experimentais de campo e de mapeamentos de feições erosivas lineares (sulcos, ravinas e voçorocas) em setor de Cuesta.

Compreende-se que, no contexto do estado de São Paulo, cabe atenção à unidade geomorfológica das Cuestas Basálticas, a qual apresenta acentuada suscetibilidade a processos degradacionais como a erosão (KERTZMAN et al., 1995). Ainda, o solapamento e os processos de vertente, que são intrínsecos a estes setores, disponibilizam um conjunto de sedimentos, os quais, em parte, se acumulam no sopé cuestiforme, caracterizando-se como depósitos coluvionares (PENTEADO, 1983; CASSETI, 1994), nos quais se desenvolvem processos erosivos lineares, conforme constataram Pinton (2016) em Analândia (SP) e Mathias (2016) em São Pedro (SP). Somada a essa questão, municípios alocados na referida província geomorfológica no estado de São Paulo apresentam significativo uso das terras, como por exemplo, em Analândia onde 34\% do seu território se destina as pastagens (IEA, 2016/17).

\section{2 ÁREA DE ESTUDO}

A área de estudo constitui-se em uma bacia hidrográfica com $1.9 \mathrm{~km}^{2}$, localizada no município de Analândia (SP), posicionada, segundo o mapa geomorfológico do estado de São Paulo (IPT, 1981), na província das Cuestas Arenítico-Basálticas (Figura 1). Constitui-se em parte da Alta Bacia do Córrego Santa Terezinha, o qual é afluente do Rio Corumbataí.

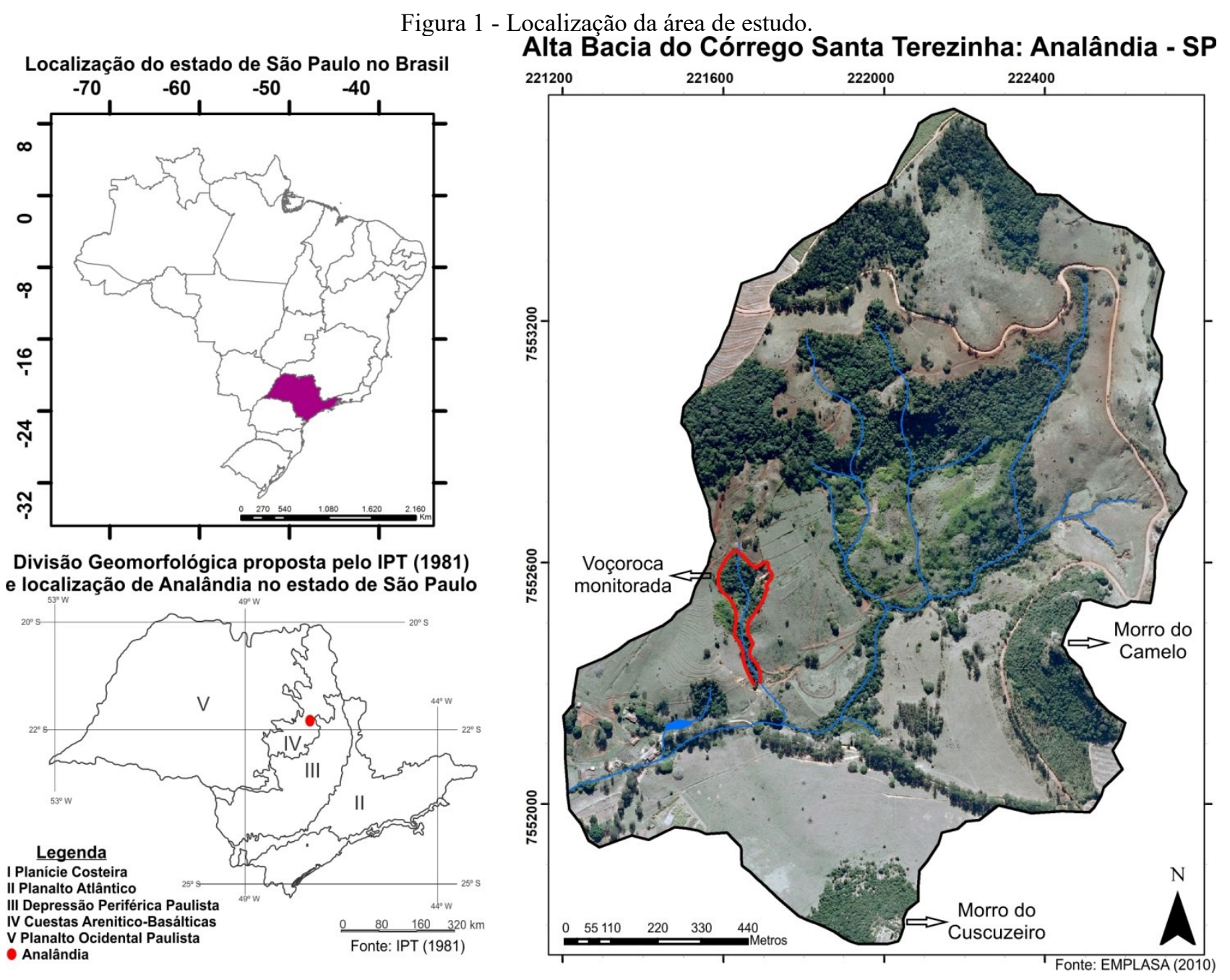

Fonte: IPT (1981); EMPLASA (2010).

Localmente, identifica-se o relevo da área como um setor de transição entre a Depressão Periférica Paulista e as Cuestas Arenítico-Basálticas. O primeiro compartimento constitui-se em uma área rebaixada por processos erosivos, sendo delimitado a leste pelas terras altas do Planalto Atlântico e a oeste pelas cuestas. O 
segundo origina-se na borda dos derrames basálticos de São Paulo e apresenta-se como elevada e festonada cuesta, tendo a leste a área de circundenudação paulista e a oeste o Planalto Ocidental (ALMEIDA, 1974).

A área pesquisada posiciona-se no setor leste da Bacia Sedimentar do Paraná, unidade classificada como a segunda maior bacia sedimentar do Brasil (CASSETI, 1994), com pacote sedimentar de aproximadamente sete mil metros de espessura (MILANI, et al. 2007). No que se refere à litologia, a área de estudo está localizada sobre as formações Itaqueri e Santa Rita do Passa Quatro, além de possuir afloramentos dos depósitos mesozóicos do Grupo São Bento, compreendidos pelas formações Pirambóia, Botucatu e Serra Geral (INSTITUTO GEOLÓGICO, 1984). A Formação Itaqueri constitui-se em uma formação pós-basáltica, dotada de arenitos com cimentação argilosa, carapaças ferruginosas, folhelhos e conglomerados (FACINCANI, 2000). Já a Formação Santa Rita do Passa Quatro tem sua origem atrelada aos depósitos cenozóicos, sugerindo uma deposição com características colúvio-aluvial, formada por sedimentos de areias finas (FACINCANI, 2000). A Formação Pirambóia é majoritariamente composta por arenitos médios a muito grossos, conglomerados e clastos centimétricos de argila, características que remetem a sedimentação de rios entrelaçados, apresentando também depósitos eólicos subordinados (CÔRTES; PERINOTTO, 2015). Ainda, a Formação Botucatu tem sua deposição associada a um ambiente dominantemente desértico, com intercalações de sedimentos fluviais e lacustres (SCHNEIDER et al., 1974) e estratificação cruzada (ZAINE, 1994). Por fim, a Formação Serra Geral compreende a sequência de rochas vulcânicas, dominantemente composta por lavas basálticas, de composição toleítica e coloração cinza a preta, sendo intercalada por delgadas camadas de arenitos intertrapianos (ZAINE, 1994).

Em relação aos solos, Koffler et al. (1992) identificaram no front da cuesta uma associação entre Neossolos Litólicos Eutróficos e Nitossolos Eutróficos ou Distróficos da Unidade Estruturada. Já no setor de tálus registram-se Latossolos Vermelho-Amarelo Álicos da Unidade Coqueiro, Argissolos Vermelhos Distróficos da Unidade Barão Geraldo e Nitossolos Eutróficos ou Distróficos da Unidade Estruturada (KOFFLER et al., 1992). Por fim, no reverso, identificam-se os Argissolos Vermelho-Amarelo Distróficos da Unidade Santa Clara, os Latossolos Vermelho Amarelo Álicos da Unidade Itororó e os Plintossolos Pétricos Concrecionários (KOFFLER et al., 1992).

Sobre tais condições morfológicas, pedológicas e litológicas, encontravam-se fragmentos de Cerrado, confinados em pequenas áreas e em unidades de conservação, e de Mata Atlântica, que estão normalmente associados às manchas de Nitossolos, provenientes da Formação Serra Geral (TROPPMAIR, 2000). Na área do front da cuesta, devido à sua topografia, predomina a Mata Latifoliada Tropical de Encosta que apresenta espécies arbóreas de porte médio (10 a 15 metros), com sistema radicular pouco profundo. Ainda, o capeamento arenítico do reverso da cuesta possibilita ao solo da região alta taxa de infiltração de água, abastecendo fortemente o lençol freático que dá origem a diversas nascentes e pequenos riachos que possibilitam a formação de Matas de Grotão ou Galeria (TROPPMAIR, 2000).

Em relação ao clima, Analândia possui ocorrência de chuvas, em média, durante 82 dias do ano, totalizando média pluviométrica anual de $1.272,7 \mathrm{~mm}$. O mês mais chuvoso do ano constitui-se em janeiro, no qual o índice pluviométrico ultrapassa $215 \mathrm{~mm}$, tendo como mês mais seco julho ou agosto, com média pluviométrica que alcança os $30,9 \mathrm{~mm}$. Ainda a temperatura média da área encontra-se entre 19 e $18,5^{\circ} \mathrm{C}$, ocorrendo no mês de janeiro temperaturas médias na casa dos $22^{\circ} \mathrm{C}$ e no mês de julho temperaturas médias na casa dos $15,5^{\circ} \mathrm{C}$ (BRINO, 1973). Segundo Monteiro (1973), a região de estudo se insere na subunidade intitulada de Centro-Norte, com climas regionais tropicais alternadamente secos e úmidos, os quais fazem parte dos climas zonais controlados por massas equatoriais e tropicais. Santos, Fontão, Souza (2020) avaliando anos úmidos e secos, constataram que as passagens frontais são responsáveis pela maior umidade; já o domínio de massas de ar tropical produziu tempo estável e longas sequencias de dias secos, resultando em ano seco. Os autores ainda afirmam que a orografia, derivada do relevo de cuesta, "apresentou uma significativa influência nas precipitações" (SANTOS; FONTÃO; SOUZA, 2020, p. 144)

Por fim, no que concerne ao uso e ocupação da terra, Pinton (2011), em estudo aplicado à bacia do Córrego Cavalheiro, área vizinha ao setor analisado, constatou que desde 1962 o uso da terra predominante constitui-se em pastagens, com predominância de pastos limpos destinados à pecuária. Já em 2007, as pastagens continuaram como o uso da terra predominante, no entanto registrou-se a chegada da cultura de cana-de-açúcar e um pequeno aumento na área ocupada por mata. 


\section{MATERIAIS E MÉTODOS}

Para desenvolver as cartas de síntese a fim de avaliar o potencial dos terrenos ao avanço da erosão linear foram utilizadas as informações dos seguintes documentos cartográficos (Figura 2):

a) Cartas de Características e Comportamento dos Materiais para os períodos úmido e seco (STEFANUTO, 2019), as quais se constituem em um compilado de dados referentes à granulometria, infiltração, resistência à penetração e permeabilidade dos solos. Essas cartas são fruto de dados de campo obtidos a partir de uma malha amostral de 48 pontos, nos quais se realizaram coletas para análise granulométrica (ABNT NBR 7181:2016) e para a análise da permeabilidade (ABNT NBR 14545:2000), experimentos com o penetrômetro de Stolf para avaliar a resistência dos materiais (STOLF, 2011) e experimentos com o infiltrômetro de Hills (GUERRA, 2002). Os dados levantados possuem unidades de medidas diferentes, assim realizou-se um processo de normalização através da técnica de logaritmização de potência de base 10. Os dados obtidos foram submetidos à análise fatorial utilizando-se o software IBM SPSS 20, seguindo os parâmetros propostos em Carvalho (2014). Os fatores foram exportados para o ArcMap, gerando-se, através da técnica de krigagem do tipo ordinária um modelo espacial das características e comportamento dos materiais durante os períodos úmido e seco. Em ambos os períodos utilizou-se o modelo de semivariograma stable, apresentando os seguintes valores para cada parâmetro: nugget 0.029498919816 (úmido) e 0.001325062733 (seco); partial sill 1.659582157195 (úmido) e 1.755016978331 (seco); range 2,244.941870071472 (úmido) e 2,244.941870071472 (seco). Assim, os valores apresentados na legenda das Cartas de Características e Comportamento dos Materiais (Figura 2) são fruto da normalização e da análise fatorial, sendo os maiores atribuídos às condições de maior resistência e granulometria mais fina (silte e argila) dos materiais e os menores valores a granulometria arenosa (areia grossa, fina e total). Convém ainda destacar que foram utilizadas duas cartas diferentes, uma para o período úmido e outra para o período seco. Os experimentos de campo demonstram que o comportamento do material apresenta ampla variação de acordo com os períodos e isso significa diferenças no potencial ao desenvolvimento das feições erosivas lineares. Assim, as cartas de síntese produzidas refletem essa concepção (Figura 2).

b) Carta de Fluxo Acumulado do Escoamento Superficial (STEFANUTO, 2019), a qual foi gerada a partir de um modelo digital de elevação (MDE) organizado por meio de dados obtidos com as cartas topográficas produzidas pelo Instituto Geográfico Cartográfico do Estado de São Paulo (IGC) de 1979, em escala de 1:10.000, folhas Serra da Estrela (SF-23-Y-A-I-2-NO-E) e Analândia I (SF-23-Y-A-I-2-NO-F). Esse modelo foi adicionado ao software ArcView 3.0, o qual processou os dados de fluxo através do algoritmo MD-Multiple Flow (Figura 2);

c) Carta de Declividade (STEFANUTO, 2019), gerada a partir do processamento de uma Triangulated Irregular Network (TIN) através da ferramenta Slope. A base de dados topográficos foi a mesma mencionada anteriormente, a partir de cartas topográficas produzidas pelo IGC;

d) Carta de Uso e Ocupação da Terra de 2019 (STEFANUTO, 2019), desenvolvida a partir da interpretação de ortofotos digitais de 2010, fornecidas pela Empresa Paulista de Planejamento Metropolitano (EMPLASA), atualizadas a partir das imagens de 2019 disponíveis na extensão Portable Basemap Server versão 3.1, do ArgGis 10.1, e trabalhos de campo para reambulação (Figura 2). 
Figura 2 - Cartas das variáveis utilizadas na atribuição dos pesos na álgebra de mapa. Carta de Características e Comportamento dos Materiais - Periodo Úmido na ${ }_{221600}^{\text {Alta Bacia do Córrego Santa Terezinha - Analândia (SP) }}$

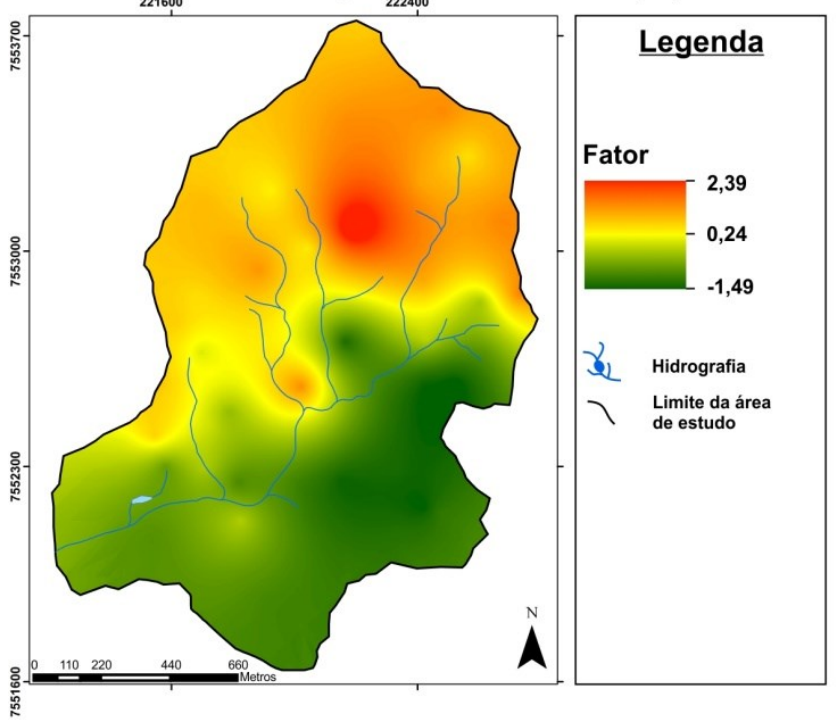

Carta de Caracteristicas e Comportamento dos Meteriais - Periodo Seco na $\underset{221600}{\text { Alta Bacia do Córrego Santa Terezinha - Analândia (SP) }}$
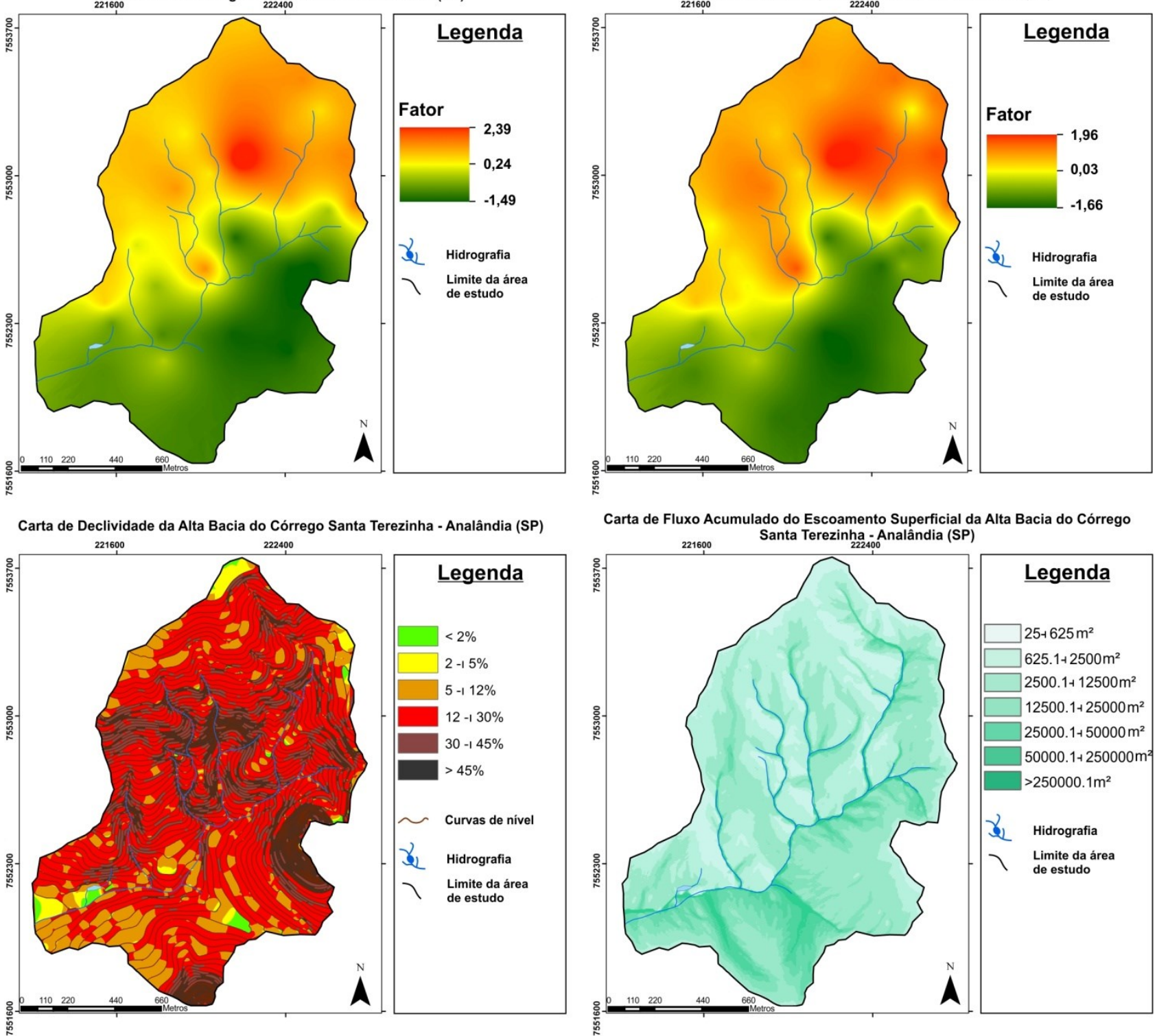

Carta de Fluxo Acumulado do Escoamento Superficial da Alta Bacia do Córrego $221600 \quad$ Santa Terezinha - Analândia (SP)
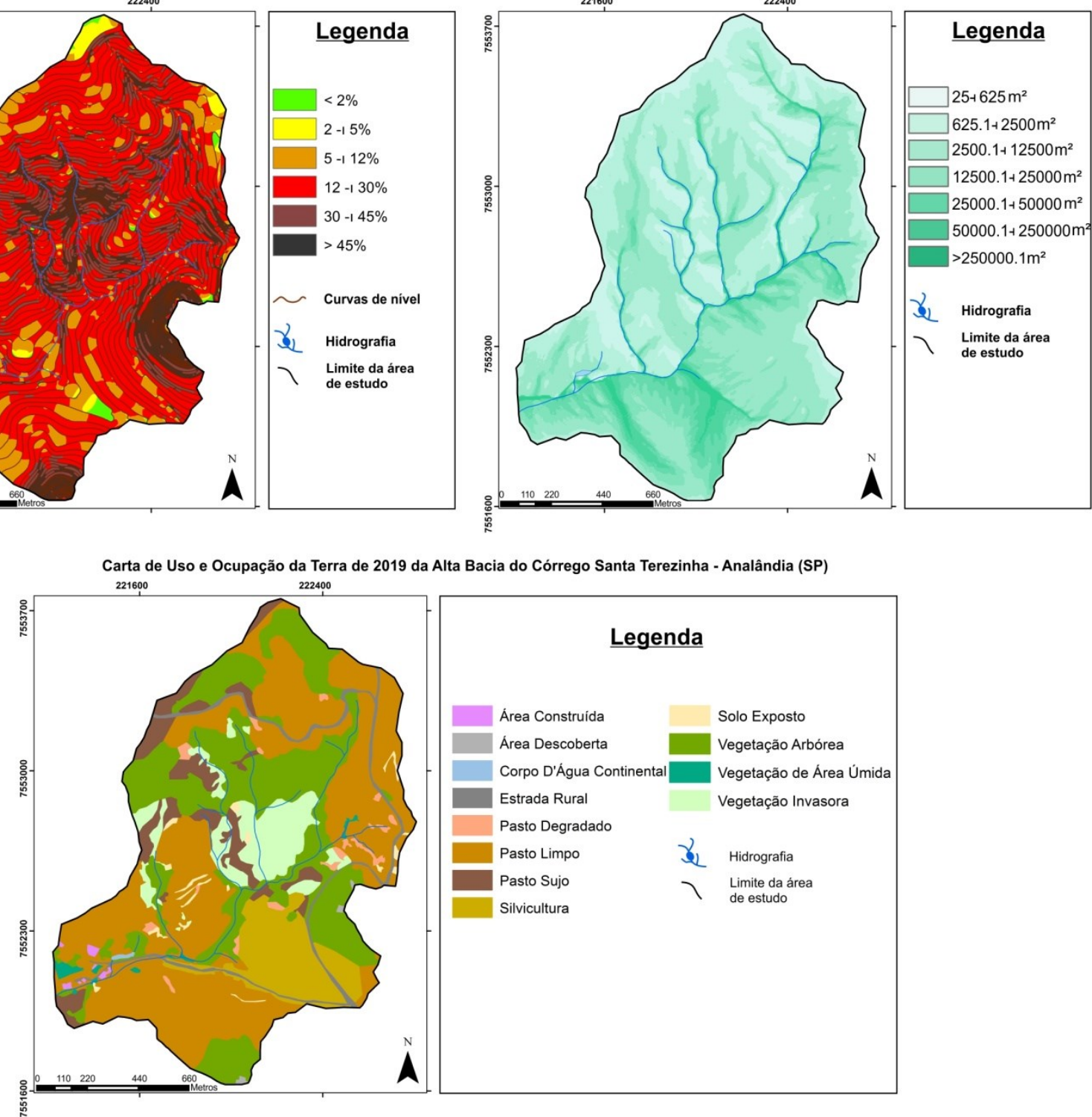

Fonte: Stefanuto (2019)

Os dados obtidos com esses documentos, em escala de 1:10.000, foram compilados por meio da ferramenta Weighted Overlay, do software ArcGis 10.1. A opção por essa ferramenta baseia-se nos resultados 
significativos obtidos por Zanatta (2018) em estudo da dinâmica erosiva linear no Planalto Ocidental Paulista. Esta ferramenta permite: i) reclassificar os valores dos pixels de cada carta de entrada, no formato raster, em uma hierarquia de pesos definidos pelo usuário; ii) atribuir uma influência a cada carta, sendo os valores dos pixels de cada raster de entrada multiplicados por esta influência percentual; e iii) gerar um novo raster de saída, a carta de síntese, por meio da sobreposição ponderada das cartas analíticas, de acordo com os pesos e as infuências estabelecidas pelo usuário (ESRI, 2016). Nesta pesquisa, tais procedimentos foram desenvolvidos de acordo com a seguinte sequencia:

i) A definição dos pesos: Para cada classe, de cada uma das cartas, foram atribuídos pesos os quais foram calculados de acordo com a área ocupada pelas feições erosivas lineares nessas classes. Para isso, foram utilizados os mapeamentos das feições erosivas desenvolvidos por Stefanuto (2019), utilizando fotografias aéreas e imagens orbitais, as quais contemplam os anos de 1962, 1988, $2010 \mathrm{e}$ 2019. Através disso, foi possível constatar quais classes, de cada carta, apresentam maior área ocupada por feições erosivas e, a partir disso, considerou-se que essas têm maior potencial ao desenvolvimento de feições erosivas (Tabela 1). Deve-se destacar que, para evitar a influência da dimensão da área ocupada por cada classe, foi realizada a normalização dos dados. O peso de cada classe foi estabelecido de duas formas diferentes:

a) Os valores da área ocupada pelas feições erosivas (sulcos, ravinas e voçorocas) em cada classe das cartas analíticas foram somados. Como tais valores eram bastante reduzidos em função da dimensão da área, esses foram transformados em coeficiente de 0 a 1 , sendo o valor 1 atribuído a classe com maior área ocupada pelas feições (Tabela 1). Realizado esse procedimento, constatou-se que a área ocupada pelas voçorocas, muito superior às demais devido à natureza da feição erosiva, se sobressaiu. Para equalizar a importância de cada tipo de feição erosiva, realizou-se então o procedimento B;

b) Considerando a área ocupada pelas feições erosivas em cada classe, com a aplicação do coeficiente de 0 a 1 em duas etapas. Assim, foi aplicado o coeficiente para a área ocupada por cada tipo de feição (sulco, ravina e voçoroca) em cada classe, de cada uma das cartas analíticas. Os três coeficientes iniciais, um para cada feição foram somados, aplicando-se, novamente, o coeficiente de 0 a 1 ao resultado da soma para obtenção do peso final. Nesse caso, o peso da área ocupada pela voçoroca, muito superior às demais, foi equalizado.

Assim, por exemplo, no caso da carta de declividade (Tabela 1): utilizando o procedimento A, constatou-se que a classe com maior área ocupada por feições erosivas era $>45 \%$, visto que as voçorocas, que apresentam área muito superior às demais formas, desenvolvem taludes íngremes que são mapeados nessa classe. Dessa forma, o maior peso (100 que equivale ao coeficiente 1 - Tabela 1) pelo procedimento A é para essa classe. Contudo, ao realizar o procedimento B, equalizando a área das feições erosivas, constatou-se que o maior peso (100) foi atribuído para a classe de 12 -30\%. Isto ocorre em função das ravinas e, principalmente, os sulcos erosivos (no caso estudado muito relacionado às pastagens) ocorrerem em classes de declive inferior; assim, nesse procedimento, o declive intenso do talude erosivo das voçorocas, que ocupam área significativa, teve menor impacto sobre a definição do peso.

Destaca-se ainda que, nesta etapa (Tabela 1), o peso atribuído a cada classe de uso e ocupação da terra foi estabelecido considerando somente as feições erosivas mapeadas em 2019, uma vez que se entende que desconsiderar uma possível recuperação ou a redução de processos erosivos em uma determinada área a partir da mudança no uso da terra é tirar a sua importância nas cartas de síntese. Ressalta-se, ainda, que as classes área construída, área descoberta, corpo d'água continental e silvicultura não apresentaram feições erosivas mapeadas, atribuindo-se o valor mínimo 1 aos pixels correspondentes. 
Tabela 1 - Pesos atribuídos às classes de cada variável. Os valores foram gerados originalmente através do coeficiente de 0 a 1 e multiplicados por 100 para fins de inserção do ArcGis. A escala de valores varia de 1 a 100.

\begin{tabular}{|c|c|c|c|c|c|}
\hline \multirow[t]{2}{*}{ Carta } & \multirow[t]{2}{*}{ Classe } & \multicolumn{2}{|c|}{ Pesos } & \multicolumn{2}{|c|}{ Influência (\%) } \\
\hline & & Técnica A & Técnica B & & \\
\hline \multirow{4}{*}{$\begin{array}{l}\text { Materiais (período } \\
\text { úmido) }\end{array}$} & 1 & 8 & 28 & \multirow{12}{*}{25} & \multirow{12}{*}{16,66} \\
\hline & 2 & 36 & 73 & & \\
\hline & 3 & 100 & 100 & & \\
\hline & 4 & 30 & 57 & & \\
\hline \multirow{8}{*}{ Materiais (período seco) } & 5 & 1 & 22 & & \\
\hline & 6 & 1 & 32 & & \\
\hline & 1 & 12 & 33 & & \\
\hline & 2 & 48 & 85 & & \\
\hline & 3 & 91 & 100 & & \\
\hline & 4 & 100 & 87 & & \\
\hline & 5 & 2 & 33 & & \\
\hline & 6 & 3 & 38 & & \\
\hline \multirow{7}{*}{ Fluxo acumulado } & $25-625$ & 40 & 75 & \multirow{7}{*}{25} & \multirow{7}{*}{16,66} \\
\hline & $625,1-2.500$ & 16 & 61 & & \\
\hline & $2.500,1-12.500$ & 32 & 80 & & \\
\hline & $12.500,1-25.000$ & 20 & 75 & & \\
\hline & $25.000,1-50.000$ & 16 & 53 & & \\
\hline & $50.000,1-250.000$ & 100 & 100 & & \\
\hline & $>250.000,1$ & 11 & 45 & & \\
\hline \multirow{6}{*}{ Declividade } & $\leq 2 \%$ & 20 & 54 & \multirow{6}{*}{25} & \multirow{6}{*}{16,66} \\
\hline & $2 \vdash 5 \%$ & 22 & 42 & & \\
\hline & $5 \vdash-12 \%$ & 19 & 59 & & \\
\hline & $12-30 \%$ & 49 & 100 & & \\
\hline & $30-45 \%$ & 95 & 97 & & \\
\hline & $>45 \%$ & 100 & 81 & & \\
\hline \multirow{8}{*}{ Uso e ocupação da terra } & Estrada rural & 1 & 1 & \multirow{8}{*}{25} & \multirow{8}{*}{50} \\
\hline & Pasto degradado & 88 & 100 & & \\
\hline & Pasto limpo & 4 & 7 & & \\
\hline & Pasto sujo & 1 & 6 & & \\
\hline & Solo exposto & 35 & 60 & & \\
\hline & Vegetação arbórea & 22 & 8 & & \\
\hline & Vegetação de área & 100 & 36 & & \\
\hline & Vegetação invasora & 7 & 4 & & \\
\hline
\end{tabular}

Fonte: Os autores (2021)

ii) A influência de cada carta: Para esse trabalho (Tabela 1), foram testados valores de influência igual para cada uma das cartas (25\%); assim como, pautando-se em uma perspectiva antropogeomorfológica (NIR, 1983), influência de 50\% para o uso e ocupação da terra, que representa a ação antropogênica, e 50\% para as variáveis físicas (declividade, fluxo acumulado de superfície e características e comportamento dos materiais durantes os períodos úmido ou seco). Assim, buscou-se avaliar se a erosão é influenciada de forma equânime por fatores físicos e antrópicos ou se os fatores antrópicos são mais preponderantes para a criação de feições erosivas lineares.

iii) As cartas de síntese: Foram geradas diversas cartas através da ferramenta Weighted Overlay: quatro cartas para período úmido e quatro para períodos secos, sendo que em cada cenário variou-se a influência ( $25 \%$ para cada carta ou $50 \%$ para o uso da terra e $25 \%$ para variáveis físicas) e os procedimentos para o cálculo do peso das classes. Assim, têm-se duas condições de umidade $\mathrm{X}$ dois sistemas de influência $\mathrm{X}$ dois procedimentos para o cálculo do peso, resultando no total de oito cartas de síntese (Quadro 1). 
Quadro 1 - Parâmetros das Cartas de Potencial ao Avanço Erosivo Linear

\begin{tabular}{|l|l|l|c|}
\hline \multicolumn{1}{|c|}{ Cartas } & \multicolumn{1}{|c|}{ Período } & \multicolumn{1}{|c|}{ Influência } & $\begin{array}{c}\text { Técnica de cálculo do } \\
\text { peso }\end{array}$ \\
\hline Carta A & Seco & 25\% para cada variável & A \\
\hline Carta B & Úmido & 25\% para cada variável & A \\
\hline Carta C & Seco & 25\% para cada variável & B \\
\hline Carta D & Úmido & $25 \%$ para cada variável & A \\
\hline Carta E & Seco & $50 \%$ para o uso da terra e $50 \%$ para demais variáveis & A \\
\hline Carta F & Úmido & $50 \%$ para o uso da terra e $50 \%$ para demais variáveis & B \\
\hline Carta G & Seco & $50 \%$ para o uso da terra e 50\% para demais variáveis & B \\
\hline Carta H & Úmido & $50 \%$ para o uso da terra e 50\% para demais variáveis & \\
\hline
\end{tabular}

Fonte: Os autores (2021)

Ainda, os dados das cartas geradas foram organizados em seis classes de potencial ao avanço erosivo linear (Muito Fraco, Fraco, Médio, Forte, Muito Forte e Extramente Forte). O número de classes foi estabelecido, inicialmente, a partir do uso da função Standard Deviation. No entanto, como havia a necessidade de se comparar os 8 documentos cartográficos produzidos e o número de classes sugerido pelo Standard Deviation apresentava variação (entre 5 e 7), estabeleceu-se um número médio de classes a ser utilizado em todos os documentos. Para definir o intervalo das seis classes, optou-se pela função Natural Breaks, a qual busca identificar variações numéricas relevantes para gerar os limites das classes e apresentou bons resultados em estudos sobre erosão desenvolvidos por Zanatta (2018).

Por fim, tais cartas foram submetidas a procedimentos de verificação a partir da hipótese de que as áreas mapeadas nas cartas síntese como de maior potencial à erosão linear deveriam coincidir espacialmente com os setores de maior ocorrência das feições erosivas (sulcos, ravinas e voçorocas) e de maior valor de erosão do talude de uma voçoroca (Figura 1), monitorada durante 21 meses por Stefanuto (2019). A partir das orientações de Guerra (2002) e Mathias (2016), foram instalados pinos de monitoramento do talude erosivo na principal frente de evolução da voçoroca. A cada três meses realizou-se o monitoramento do talude erosivo, quantificando a distância entre os pinos e o talude erosivo, de forma analógica e digital por meio de uma Estação Total Spectra Precision Focus 6. Assim, foram quantificados os milímetros de recuo do talude ao longo do período analisado em cada classe de potencial ao avanço erosivo das cartas de síntese.

Ainda, utilizando os mapeamentos das feições erosivas desenvolvidos por Stefanuto (2019), quantificou-se a área de ocorrência de tais feições em cada classe das cartas de síntese, através da ferramenta Extract by mask, obtendo-se os valores em $\mathrm{m}^{2}$ por tipo de feição erosiva em cada classe de potencial ao avanço erosivo. Considerou-se como melhor resultado as cartas de síntese que apresentaram as classes mais altas de potencial erosivo coincidindo espacialmente com os setores de maior erosão do talude da voçoroca, assim como de maior incidência de feições erosivas lineares (sulcos, ravinas, voçorocas).

\section{RESULTADOS}

A partir dos referidos procedimentos metodológicos e técnicos gerou-se um conjunto de cartas de síntese (Figura 3). As cartas A e B com influência de 25\% para cada variável, considerando a área das feições, em período seco e úmido, respectivamente, demarcaram uma faixa de maior potencial ao avanço erosivo na porção central da bacia hidrográfica, sendo está mais extensa no período seco em relação ao período úmido. Ainda, no setor norte, em ambas as cartas, foi identificada uma fraca tendência ao avanço erosivo. Já a cartas de síntese $\mathrm{C}$ e $\mathrm{D}$, com influência de $25 \%$ para cada variável, utilizando a dupla aplicação do coeficiente de 0 1, apresentaram áreas mais extensas de alta tendência ao avanço erosivo, principalmente no setor sudoeste, em comparação às cartas anteriores. Já em relação às zonas de fraco potencial ao avanço erosivo, identificou-se a extremidade do setor norte e nordeste como áreas de destaque. As cartas de síntese $\mathrm{E}$ e $\mathrm{F}$ com influência de $50 \%$ para o uso da terra, utilizando a área das feições, apresentaram os setores fortes e extremamente fortes de forma pontual, dificultando a identificação de uma zona de maior potencial ao avanço erosivo; as classes de médio, fraco e muito fraco potencial ao avanço erosivo foram predominantes. Por fim, nas cartas $\mathrm{G}$ (seco) e $\mathrm{H}$ 
(úmido), com dupla aplicação do coeficiente de 0-1 e influência de 50\% para o uso da terra, também foram identificados os setores fortes e extremamente fortes de forma pontual, ocorrendo uma predominância de classes com baixo potencial ao avanço erosivo.

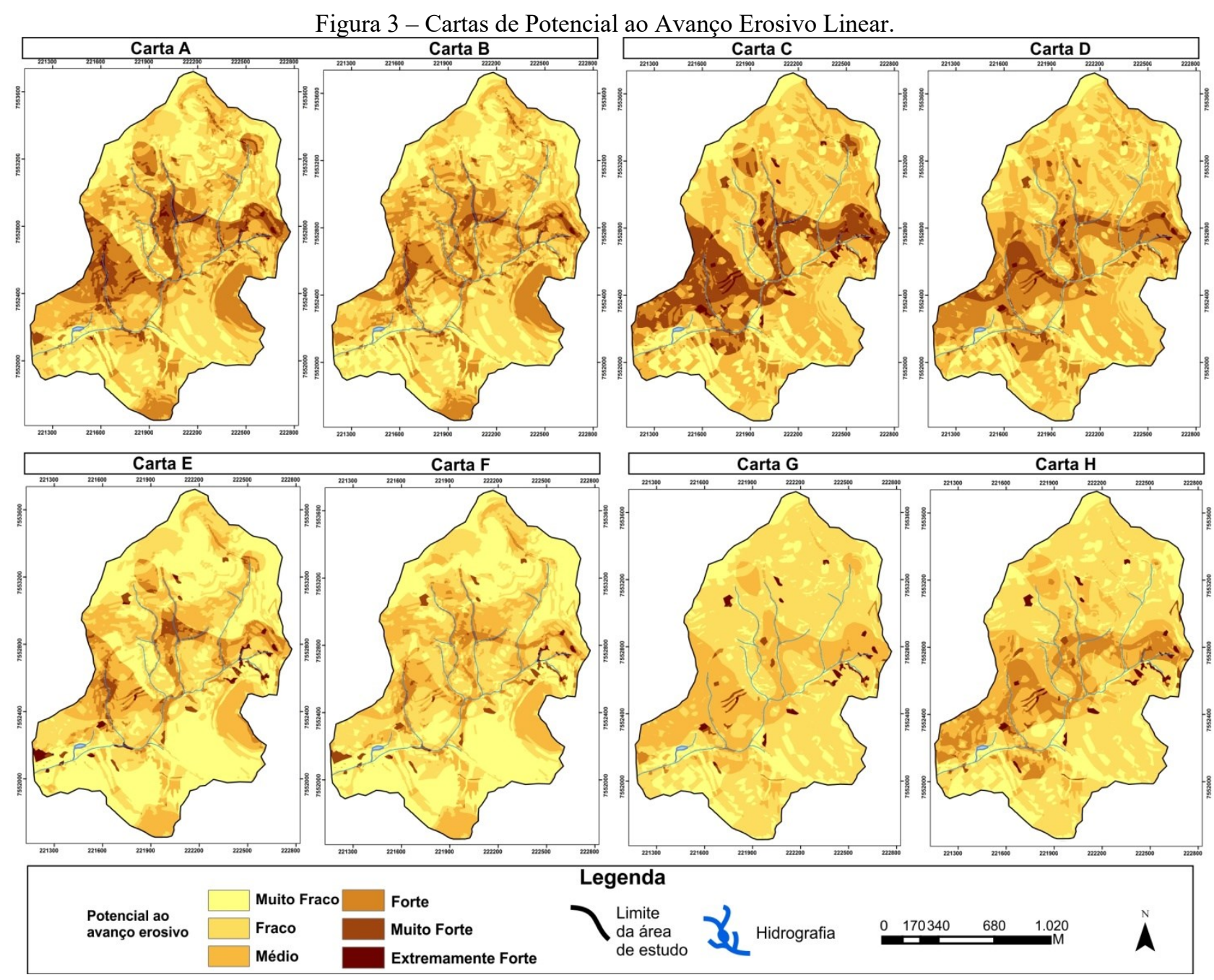

Fonte: Os autores (2021)

O material cartográfico foi avaliado a partir da hipótese de que as áreas com maior potencial ao avanço erosivo devem coincidir com os setores de maior ocorrência de feições erosivas lineares e de maior erosão do talude erosivo da voçoroca monitorada.

Desta forma, primeiramente, verificaram-se as cartas através da área de ocorrência de feições erosivas lineares na bacia hidrográfica, confrontando os dados das cartas geradas com o mapeamento das feições erosivas realizado por Stefananuto (2019, Figura 4). O autor constatou que as feições erosivas concentram-se no setor central da área, em uma faixa que se estende de leste a oeste, a qual se caracteriza como o setor de transição entre os materiais mais argilosos ao norte e os mais arenosos ao sul, em situação topográfica de sopé do front cuestiforme e dos morros testemunhos, fato que pode caracterizar tal faixa como receptora de fluxos superficiais com significativa energia gravitacional agregada (Figura 2).

Para a avaliação das cartas síntese, estas foram analisadas em duplas, considerando conjuntamente o comportamento erosivo nos períodos seco e úmido. Assim, compreende-se que a dupla formada pelas cartas C e D (influência de $25 \%$ para cada variável, utilizando a dupla aplicação do coeficiente de 0 a 1 , em período úmido e seco) apresentou os melhores resultados na análise comparativa (Figura 5). Os dados das cartas de síntese C e D apresentam uma maior concordância entre as diversas feições erosivas e a classe extremamente forte de potencial erosivo, fato apontado pela dimensão das barras de cor marrom no gráfico B da figura 5 . Nas cartas A e B (influência de $25 \%$ para cada variável, considerando a área das feições, em período seco e úmido, Figura 5A) a única feição a atingir boa correspondência foi a do tipo voçoroca. Já a cartas E, F, G e H (Figura $5 \mathrm{C}$ e D), as quais foram geradas considerando $50 \%$ de influência para os dados de uso da terra, 
evidenciaram comportamento similar. As cartas E e H também apresentaram boa resposta à validação, no entanto, como mencionado, optou-se em analisar os documentos cartográficos dos períodos seco e úmido conjuntamente, impossibilitando classificar as cartas $\mathrm{E}$ e $\mathrm{H}$ como adequadas à hipótese em função de seus pares (cartas F e G, respectivamente).

Figura 4 - Carta de feições erosivas lineares.

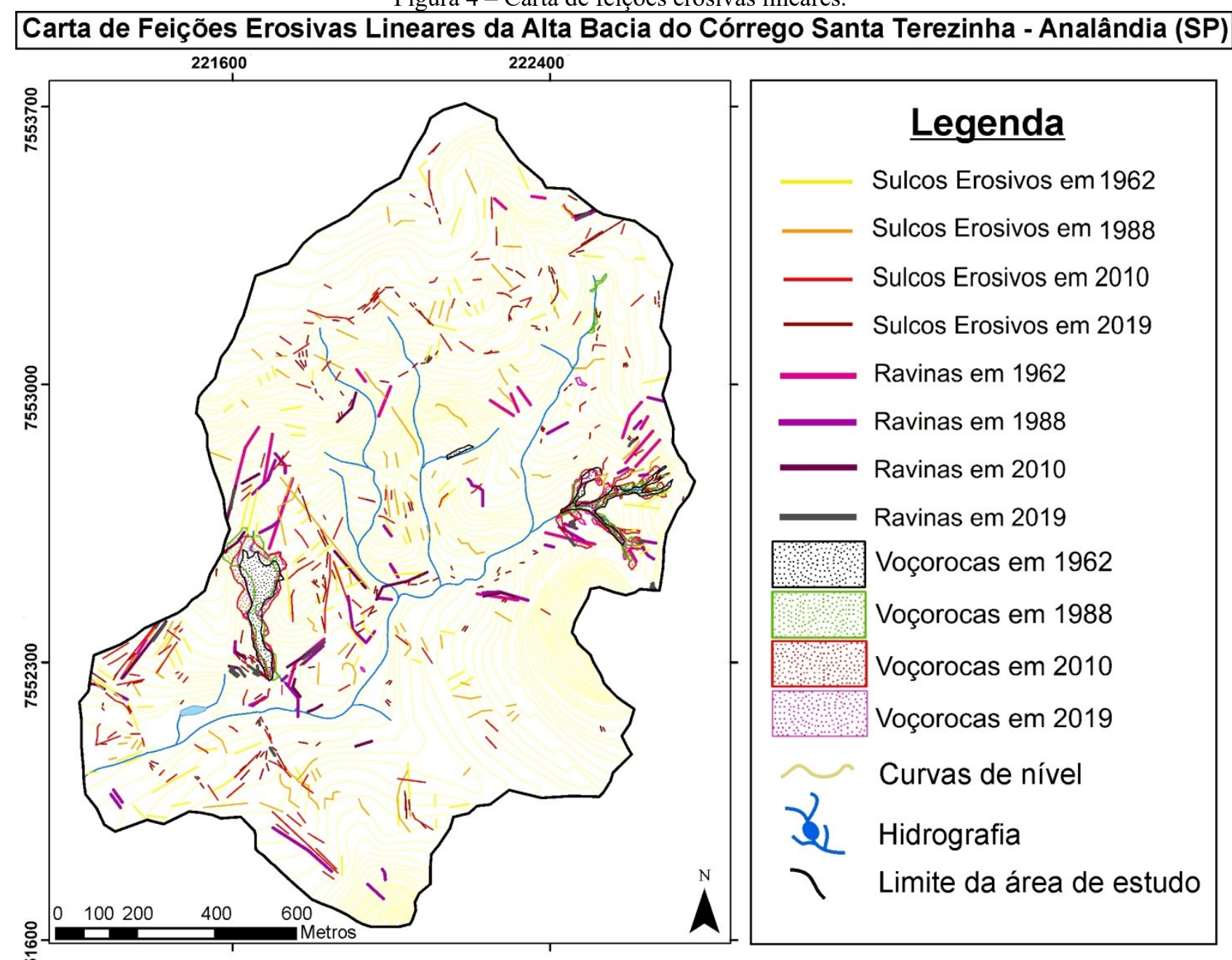

Fonte: Stefanuto (2019). 
Figura 5 - Área ocupada pelas feições erosivas lineares por classe de potencial ao avanço erosivo linear.

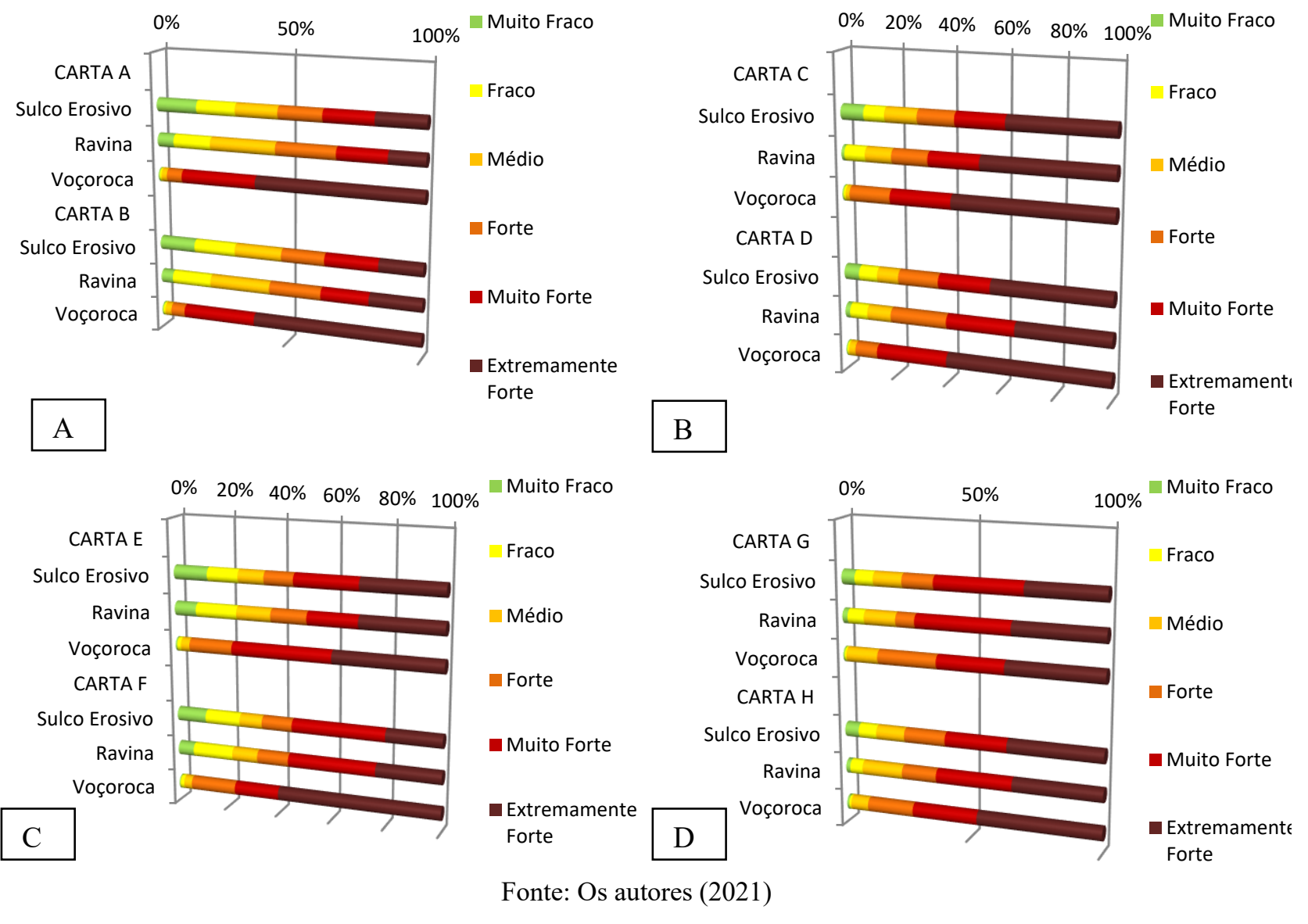

Ainda, às cartas de síntese foram submetidas à verificação através dos dados de evolução do talude erosivo da voçoroca monitorada (Figura 6). As cartas A e B (Figura 7) obtiveram o melhor ajuste à hipótese, apresentando uma distribuição significativa de recuo do talude entre as classes de potencial ao avanço erosivo mapeadas como forte, muito forte e extremamente forte (Figura 8). Ainda, apesar da Carta C apresentar bons resultados (Figura 8), no conjunto com a carta D considera-se que não houve uma reposta detalhada o suficiente para refletir o recuo do talude, uma vez que a classe média da carta $\mathrm{D}$ se sobrepõem a vários pontos de significativa erosão do talude. Por fim, as cartas E, F, G e H (Figura 8) apresentaram uma série de pontos com erosão considerável do talude na classe média, além de baixa representatividade nas classes de tendência ao avanço muito forte e extremamente forte. 
Figura 6 - Posição da voçoroca monitorada (A), pontos de monitoramento (B) e fotos do talude erosivo (C e D).
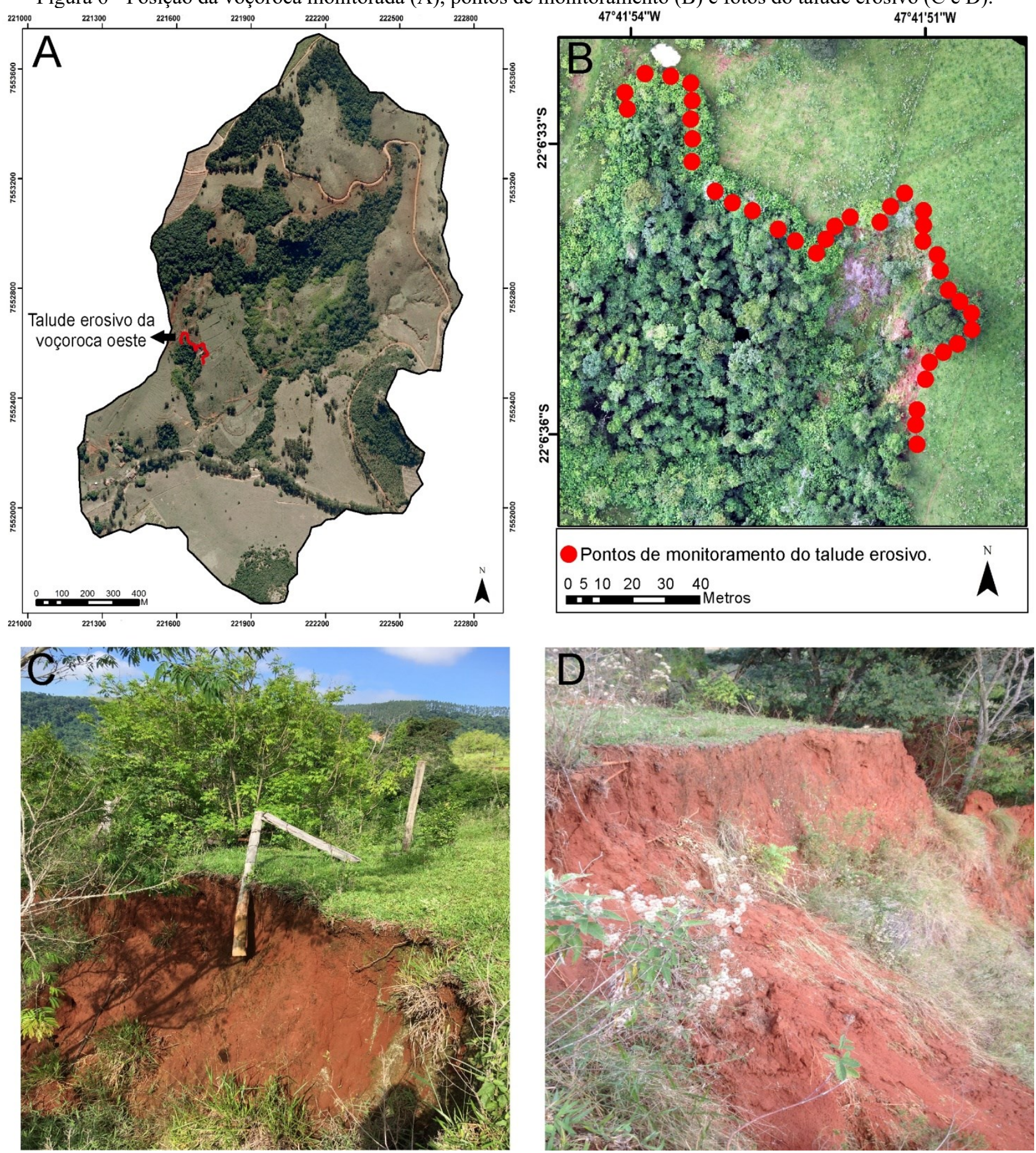

Fonte: Os autores (2021). 
Figura 7 - Evolução do talude erosivo e mapeamento do potencial ao avanço erosivo linear. Observam-se os dados, em verde, dos pontos de monitoramento sobrepostos às cartas de potencial ao avanço erosivo linear.

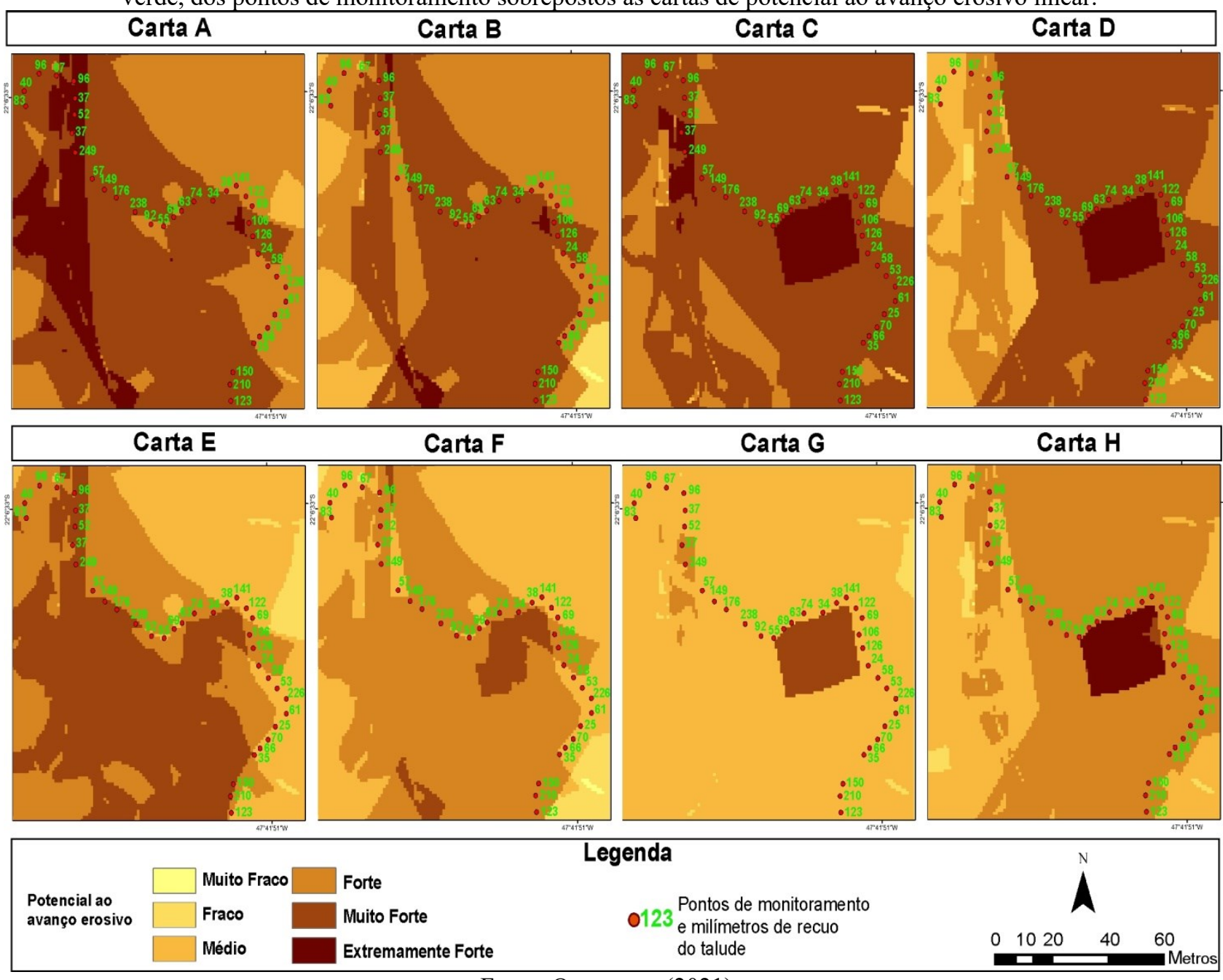

Fonte: Os autores (2021).

Figura 8- Evolução do talude erosivo em cada classe de potencial ao avanço erosivo linear.

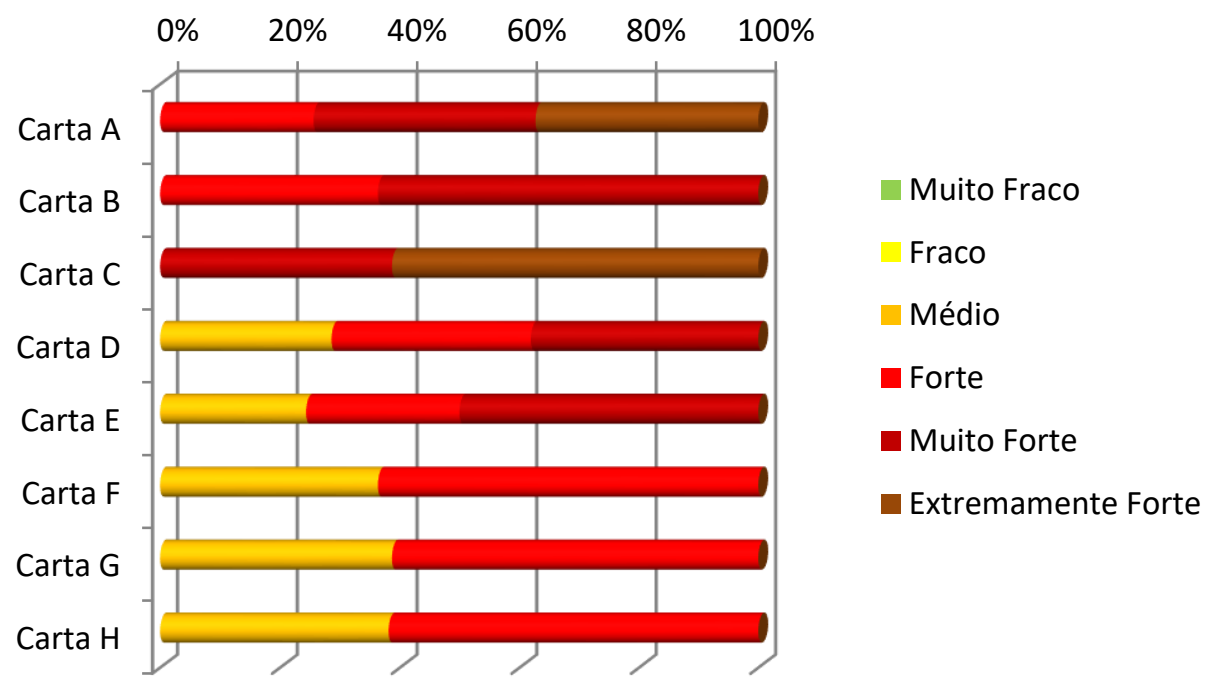

Fonte: Os autores (2021). 


\section{ANÁLISE DOS RESULTADOS}

Os resultados apresentados permitiram identificar potencialidades diferenciadas dos procedimentos metodológicos de acordo com as técnicas utilizadas para o estabelecimento dos pesos. A técnica A possibilitou respostas mais precisas em setores de voçorocamento (Carta A e B, Figuras 7 e 8); e a técnica B foi responsável por uma boa reposta quando se pretende compreender o potencial para o desenvolvimento de todos os tipos de feições (Carta C e D, Figura 5).

Contudo, destacam-se algumas questões que comprovam a necessidade de avaliação dos produtos cartográficos em campo. Neste sentido, no processo de validação por meio do talude erosivo (Figura 7 e 8), identificou-se uma área com dados distorcidos, a qual se constitui na porção oeste do talude (Figura 9). Contatou-se na Carta A (e em menor proporção nas outras) uma faixa de potencial ao avanço erosivo extremamente forte em um setor com a maioria dos pontos registrando reduzido recuo do talude (Figura 9), com valores que atingiam, em sua maioria, no máximo $96 \mathrm{~mm}$ (enquanto outros setores monitorados chegaram a mais de $200 \mathrm{~mm}$ de recuo). O ponto com evolução de $249 \mathrm{~mm}$ identificado no setor, pode ser analisado como uma exceção. Assim, analisando as variáveis utilizadas para composição das cartas de síntese, identificou-se uma espacialização das classes de potencial ao avanço erosivo similar aos dados de fluxo acumulado do setor (STEFANUTO, 2019), o qual apresenta valores de fluxo típicos de um canal pluvial (Figura 2), fato que permite, em algumas cartas de síntese, potencial erosivo alto. No entanto, no processo de reambulação em campo, identificou-se que o setor em questão não se caracteriza como um canal pluvial em função de uma pequena barragem feita pelo proprietário (Figura 9), a qual interfere significantemente nos fluxos superficiais do setor e consequentemente na evolução do talude erosivo. Outro fato importante é que as curvas de nível presentes na base cartográfica, ainda indicam grande concavidade no local, influenciando diretamente na carta de fluxo acumulado e, consequentemente, gerando distorções nas cartas de síntese. Portanto, tal constatação comprova a necessidade, para estudos futuros, da avaliação de construções antrópicas rurais no processo de formulação de cartas de síntese de potencial ao avanço erosivo; demonstrando também a importância de abordagens metodológicas que considerem a integração de ferramentas estatísticas e de SIG conjuntamente com dados de campo para formulação de modelos erosivos confiáveis (GHOLAMI et al., 2021). 
Figura 9 - Interferência antrópica no setor oeste da voçoroca monitorada.

\section{Carta A}
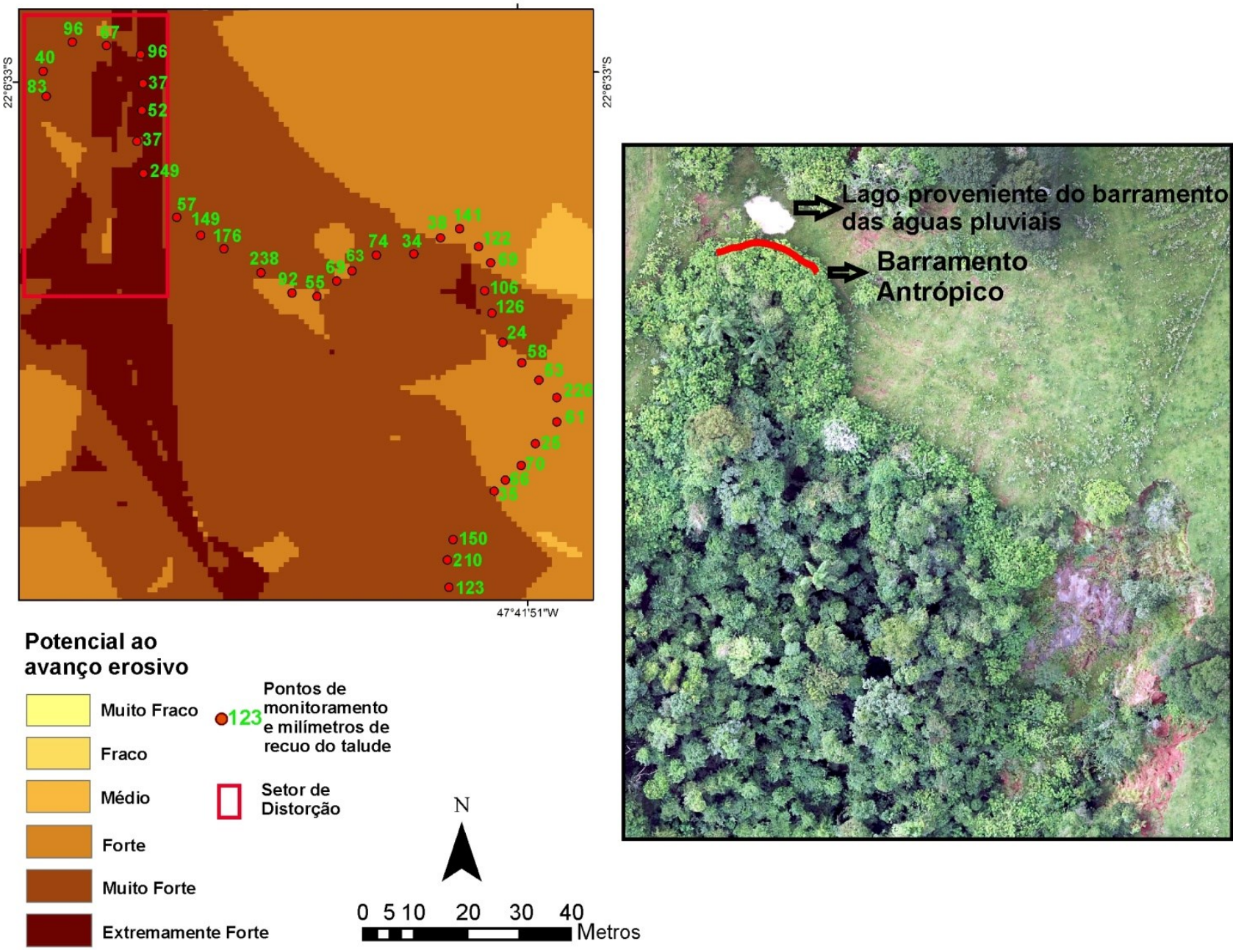

Fonte: Os autores (2021).

Outra questão é a variação das classes de potencial erosivo entre os períodos seco e úmido, fato identificado principalmente nas cartas com melhor resposta à validação (Cartas $\mathrm{A}, \mathrm{B}, \mathrm{C}$ e D). Assim, através de uma análise qualitativa da Figura 3, identificou-se um aumento na área das classes mais elevadas de potencial ao avanço erosivo nas cartas representativas do período seco (Cartas A e C), fato interessante, uma vez que pesquisa similar a esta, apresenta o período úmido com maior condição superficial para o desencadeamento erosivo (MATHIAS, 2016). Com isso, buscando compreender tal dinâmica, em campo, foram identificados setores com a presença de argilas com característica expansiva, as quais fragmentam os solos através das gretas e fendas de ressecamento (MENDES, 1993), fato que pode diminuir a resistência do material em função do aumento de espaços vazios e menor contato com a haste do Penetrômetro de Stolf utilizado para o levantamento da resistência dos solos. Neste sentido, os dados de resistência do solo à penetração compuseram, com peso relevante, as Cartas de Características e Comportamento dos Materiais (Figura 2), sendo esta uma das variáveis para formulação das cartas de síntese. Portanto, compreende-se que os solos argilosos da área de estudo podem apresentar menor resistência durante o período seco, fato que pode justificar, em parte, o maior potencial ao desenvolvimento erosivo registrado nas Cartas A e C. Este detalhe, constatado em campo, sugere que o tipo de argila pode condicionar a afirmação feita por alguns estudos que apontam uma relação inversamente proporcional entre o percentual de argila e a taxa de erosão do solo (GHOLAMI et al., 2021).

Por fim, destacam-se as cartas que receberam influência de 50\% para o uso da terra no momento da formulação. A hipótese inicial para tal procedimento foi de que a ação humana na área de estudo teria uma influência significativa na evolução das feições erosivas e, desta forma, a variável representativa da ação antrópica (uso da terra) teria um peso mais relevante na dinâmica erosiva, afirmativa que é corroborada por estudos que indicam influência direta do uso da terra em processos geomorfológicos como o splash e o runoff 
(CHU et al., 2019; GHOLAMI et al., 2021). No entanto, não se verificou neste estudo tal relação de forma direta. As cartas E, F, G e H não apresentaram as melhores respostas aos processos de validação (Figuras $5 \mathrm{e}$ 7). Desta forma, entende-se que a dinâmica erosiva atuante no setor analisado evolui e avança a partir da interação de elementos físicos e das ações humanas, fato comprovado pela validação das cartas de síntese com melhor resposta às hipóteses do estudo (Cartas A, B, C e D), nas quais se empregaram influência igual (25\%) às variáveis físicas e ao uso da terra. Neste sentido, aponta-se, como um caminho científico, a análise dos ambientes rurais a partir dos princípios da complexidade dos ambientes (MURRAY et al. 2009), os quais defendem a necessidade de avaliar a interação das variáveis naturais e humanas para a pesquisa dos diferentes sistemas terrestres.

\section{CONSIDERAÇÕES FINAIS}

As cartas de síntese apresentadas evidenciaram resposta variável a depender da técnica de preparação dos dados (técnica A ou B) e a partir da influencia atribuída a cada variável. Assim, parte dos materiais cartográficos apresentou boa resposta à validação (Cartas $\mathrm{A}, \mathrm{B}, \mathrm{C}$ e $\mathrm{D}$ ), sendo que outro conjunto não respondeu bem ao processo $(\mathrm{E}, \mathrm{F}, \mathrm{G}$ e $\mathrm{H})$. Tal informação aponta para o entendimento de que a dinâmica erosiva atuante no setor evolui e avança a partir da interação de elementos físicos e das ações humanas, já que as cartas que apresentaram melhor resultado foram aquelas que consideraram de forma equânime a influencia do uso da terra e das demais cartas voltadas para as variáveis físicas. Esse fato, no estudo de caso desenvolvido, é bastante relevante também em função da influencia do relevo cuestiforme, o qual interfere claramente no declive dos terrenos, no escoamento superficial e nos materiais de superfície que sustentam tal relevo.

Ainda, verificou-se que a avaliação do potencial ao desenvolvimento de cada tipo de feição erosiva também apresenta respostas diferentes de acordo com a técnica utilizada para estabelecer o peso das classes das cartas a serem integradas. Assim, a avaliação do potencial ao desenvolvimento de feições do tipo voçoroca apresentou melhor resultado quando empregada a técnica A; enquanto para o conjunto de feições, incluindo ravinas e sulcos erosivos, fez-se necessário equalizar a área ocupada pelo conjunto das feições quando da atribuição dos pesos. Esses resultados apontam para a necessidade de avaliar de forma mais criteriosa os terrenos quando se trata de dinâmicas erosivas lineares.

Ainda, destaca-se a necessidade, para estudos futuros, de considerar construções antrópicas rurais no processo de formulação de cartas de síntese de potencial ao avanço erosivo, uma vez que estas podem interferir diretamente na formulação de alguns dados. Também, do ponto de vista do potencial erosivo, convém enfatizar a questão referente aos períodos secos, uma vez que a depender da composição do material, com destaque para as argilas com características expansivas, a resistência do solo pode ser reduzida. Estes fatos comprovam a importância dos trabalhos de campo para a avaliação dos produtos cartográficos gerados.

Por fim, considera-se que os documentos cartográficos elaborados, assim como os procedimentos metodológicos desenvolvidos, possuem sustentação para a análise da dinâmica erosiva linear em setores de Cuesta, uma vez que parte dos produtos (Cartas A, B, C e D) apresentou bons resultados frente aos procedimentos de verificação. No entanto, este estudo foi aplicado a uma área piloto, sendo que, em pesquisas futuras, faz-se de suma importância testar a metodologia em áreas de relevo cuestiforme com atributos distintos, podendo-se ainda considerar outras variáveis, como os dados químicos dos solos (NANDI; LUFFMAN, 2012; CORRÊA et al., 2018; XIA et al., 2019) e os dados geológicos estruturais (FACINCANI, 2000).

\section{Agradecimentos}

Os autores agradecem ao financiamento concedido pela FAPESP (Fundação de Amparo à Pesquisa do Estado de São Paulo) processos n ${ }^{\circ}$ 2016/25399-1 e n ${ }^{\circ}$ 2018/09746-9 e pela CAPES (Coordenação de Aperfeiçoamento de Pessoal de Nível Superior) código de financiamento 001. 


\section{Contribuição dos Autores}

Estêvão Botura Stefanuto contribuiu com o desenvolvimento das etapas de: conceptualização, análise formal, aquisição de financiamento, investigação, metodologia, administração do projeto, redação (minuta inicial) e redação (revisão e edição). Cenira Maria Lupinacci contribui com o desenvolvimento das etapas de: conceptualização, aquisição de financiamento, metodologia, supervisão, validação, redação (minuta inicial) e redação (revisão e edição).

\section{Conflitos de Interesse}

Os autores atestam que não há conflitos de interesse.

\section{Referências}

ABNT. NBR 7181: Solo - Análise Granulométrica. Rio de Janeiro: ABNT, 2016.

ABNT. NBR 14545: Determinação do Coeficiente de Permeabilidade de Solos Argilosos a Carga Variável. Rio de Janeiro: ABNT, 2000.

AL-HAMDAN, O.Z., PIERSON, F.B., NEARING, M.A., WILLIAMS, C.J., STONE, J.J., KORMOS, P.R., BOLL, J., WELTZ, M.A. Risk assessment of erosion from concentrated flow on rangelands using overland flow distribution and shear stress partitioning. Transactions of the ASABE, v. 56, n. 2, p. 539-548, 2013.

ALMEIDA, F. F. M. de. Fundamentos Geológicos do Relevo Paulista. São Paulo: IGEOG, 1974.

BERTONI, J.; LOMBARDI NETO, F. Conservação do Solo. 8. ed. São Paulo: Ícone, 2012.

BRINO, W. C. Contribuição à definição climática da Bacia do Corumbataí e adjacências (SP), dando ênfase à caracterização dos tipos de tempo. 1973. 119 f. Tese (Doutorado em Geografia) - Faculdade de Filosofia, Ciências e Letras de Rio Claro, Rio Claro, 1973.

CARVALHO, R. F. F de. Análisis multi-proxy paleoambiental y modelización de registros sedimentarios fluviales en los Alpes Suizos. 2014. 259 f. Tese (Doutorado em Geografía, Planificación Territorial y Gestión ambiental) - Facultat de Geografia i Història, Universitat de Barcelona, Barcelona, 2014.

CASSETI, V. Elementos de Geomorfologia. Goiânia: Editora da UFG, 1994.

CHU, S.; OUYANG, J.; LIAO, D.; ZHOU, Y.; LIU, S.; SHEN, D.; WEI, X.; ZENG, S. Effects of enriched planting of native tree species on surface water flow, sediment, and nutrient losses in a Eucalyptus plantation forest in southern China. Science of the Total Environment, v. 675, p. 224-234, 2019. DOI.10.1016/j.scitotenv.2019.04.214

CHRISTOFOLETTI, A. Modelagem de sistemas ambientais. São Paulo: Edgard Blücher, 1999.

CORRÊA, E. A.; MORAES, I. C.; PINTO, S. A. F.; LUPINACCI, C. M. Evaluation of Water Erosion in Sugarcane Crops Using Erosion Plots and Photo Comparison Technics. Revista Brasileira de Geografia Física, v. 11, n. 5, p. 1761-1775, 2018. DOI.10.26848/rbgf.v11.5.p1761-1775

CÔRTES, R. A. P.; PERINOTTO, A. J. J. Fácies e associação de fácies da Formação Piramboia na região de Descalvado (SP). Geologia USP. Série Científica, v. 15, n. 3-4, p. 23-40, 2015. DOI.10.11606/issn.2316-9095.v15i3-4p23-40

COUTO, A. A.; CONCEIÇÃO F. T.; FERNANDES, A. M.; SPATTI JÚNIOR, E. P.; LUPINACCI, C. M.; MORUZZI, R. B. Land use changes associated with the expansion of sugar cane crops and their influences on soil removal in a tropical watershed in São Paulo State (Brazil). Catena. v. 172, p. 313-323, 2019. DOI.10.1016/j.catena.2018.09.001

EMPRESA PAULISTA DE PLANEJAMENTO METROPOLITANO - EMPLASA. Projeto Mapeia São Paulo. São Paulo, 2010. Color. Escala 1:25000. 
ESRI. Weighted Overlay. 2016. Disponível em: http://desktop.arcgis.com/en/arcmap/10.3/tools/spatialanalyst-toolbox/weighted-overlay.htm. Acesso em: 16 set. de 2020.

FACINCANI, E. M. Morfotectônica da depressão periférica paulista e cuesta basáltica: regiões de São Carlos, Rio Claro e Piracicaba, SP. 2000. 222 f. Tese (Doutorado em Geologia Regional) - Instituto de Geociências e Ciências Exatas, Universidade Estadual Paulista, Rio Claro, 2000.

FENDRICH, R.; OBLADEN, N. L.; AISSE, M.; GARCIAS, C. M. Drenagem e Controle da Erosão Urbana. Curitiba: Champagnat, 1997.

FOOD AND AGRICULTURE ORGANIZATION OF THE UNITED NATIONS - FAO. Status of the Word's Soil Resources. Roma, 2015

GHOLAMI, V.; SAHOUR, H.; HADIAN AMRI, M. A. Soil erosion modeling using erosion pins and artificial neural networks. Catena, v. 196, p. 104902, 1 jan. 2021. DOI.10.1016/j.catena.2020.104902

GUERRA, A. J. T. Processos Erosivos nas Encostas. In: CUNHA, S. B. da.; GUERRA, A. J. T. (Org.). Geomorfologia: Exercícios, Técnicas e Aplicações. 2 ed. Rio de Janeiro: Bertrand Brasil, 2002. p. 139155.

INSTITUTO DE ECONOMINA ARGÍCOLA - IEA. LUPA - Ocupação do Solo 2016/17. São Paulo: Secretaria de Agricultura e Abastecimento. Disponível em: < http://www.iea.agricultura.sp.gov.br/out/bilupa.php> Acesso em: 26 jun. 2020.

INSTITUTO GEOLÓGICO - IG. Folha Geológica de Corumbataí (SF-23-Y-A-I-2): Formações Geológicas de Superfície. São Paulo: Instituto Geológico, 1984. Escala 1:50.000.

INSTITUTO DE PESQUiSAS TECNOLÓGICAS DO ESTADO DE SÃO PAULO - IPT. Mapa geomorfológico do estado de São Paulo: Nota Explicativa. São Paulo: IPT, 1981. Escala 1:1.000.000.

KERTZMAN, F. F., OLIVEIRA, A. M. S., SALOMÃO, F. X. T., GOUVEIA, M. I. F., Mapa de Erosão do Estado de São Paulo. Revista do Instituto Geológico, volume especial, 31-36, 1995. DOI.10.5935/0100929X.19950008

KOFFleR, N. F.; MACHADO, M. L. de. A.;DAROS, E.; PROCHNOW, E. A. Solos da bacia do Rio Corumbataí. Rio Claro: Departamento de Cartografia e Análise da Informação Geográfica - Instituto de Geociências e Ciências Exatas, Universidade Estadual Paulista, 1992. Escala: 1:50.000.

LIMA, E. R. V. de; PINTO, S. dos A. F.; LANDIM, P. M. B. Análise multivariada e cartografia de síntese no estudo da erosão dos solos. Revista do Departamento de Geografia. n. especial, p. 40- 93, 2014. DOI.10.11606/rdg.v0i0.537

LIMBERGER, L. Abordagem Sistêmica e Complexidade na Geografia. Geografia (Rio Claro). v.15, n.2, p. 95-109, 2006.

MAFRA, N. M. C. Erosão e Planificação de Uso do Solo. In: GUERRA, A. J. T.; SILVA, A. S. da.; BOTELHO, R. G. M. (Org.). Erosão e Conservação dos Solos: Conceitos, Temas e Aplicações. Rio de Janeiro: Bertrand Brasil, 1999. p. 301-320.

MAHMOODABADI, M.; SAJJADI, S. A. Effects of rain intensity, slope gradient and particle size distribution on the relative contributions of splash and wash loads to rain-induced erosion. Geomorphology, v. 253, p. 159-167, 2016. DOI.10.1016/j.geomorph.2015.10.010

MATHIAS, D. T. Contribuição Metodológica para o Diagnóstico da Dinâmica Erosiva Linear e seu Prognóstico Evolutivo visando subsidiar Projetos de Recuperação. 2016. 178 f. Tese (Doutorado em Geografia). Faculdade de Ciências e Tecnologias, Universidade Estadual Paulista - UNESP, Presidente Prudente, 2016.

MARTINELLI, M. Mapas de Geografia e cartografia temática. São Paulo: Contexto, 2003.

MENDES, I. A. A dinâmica erosiva do escoamento pluvial na bacia do córrego Lafon - Araçatuba - SP. 1993. 171f. Tese (Doutorado em Geografia). Universidade de São Paulo, São Paulo, 1993.

MENNIS, J. (2010), Multidimensional Map Algebra: Design and Implementation of a Spatio-Temporal GIS Processing Language. Transactions in GIS. n. 14, p. 1-21. DOI.10.1111/j.1467-9671.2009.01179.x 
MONTEIRO, C.A. de F. A dinâmica climática e as chuvas no Estado de São Paulo - estudo geográfico sob forma de atlas. São Paulo: Instituto de Geografia, Universidade de São Paulo, 1973.

MILANI, E. J.; MELO, J. H. G. de; SOUZA, P. A. de; FERNANDES, L. A.; FRANÇA, A. B. Bacia do Paraná. Boletim de Geociências da Petrobras. v.15, n.2, p. 265-287, 2007.

MURRAY, A. B.; LAZARUS, E.; ASHTON, A.; BAAS, A.; COCO, G.; COULTHARD, T.; FONSTAD, M.; HAFF, P.; MACNAMARA, D.; PAOLA, C.; PELLETIER, J.; REINHARDT, L. Geomorphology, complexity, and the emerging science of the Earth's Surface. Geomorphology. v.103, p.496-505, 2009. DOI.10.1016/j.geomorph.2008.08.013

NANDI, A.; LUFFMAN, I. Erosion related changes to physicochemical properties of Ultisols distributed on calcareous sedimentary rocks. Journal of Sustainable Development. v.5, n.8, p.52-68, 2012. DOI.10.5539/jsd.v5n8p52

NIR, D. Man, a geomorphological agent: an introduction to anthropic geomorphology. Jerusalem: Katem Pub, House, 1983.

NOUWAKPO, S.K., WILLIAMS, C.J., AL-HAMDAN, O.Z., WELTZ, M.A., PIERSON, F., NEARING, M. A review of concentrated flow erosion processes on rangelands: Fundamental understanding and knowledge gaps. International Soil and Water Conservation Research. v.4, n.2, p. 75-86, 2016. DOI.10.1016/j.iswcr.2016.05.003

PENTEADO, M. Fundamentos de Geomorfologia. 3 ed. Rio de Janeiro: IBGE, 1983.

PINTON, L. de G. A Antropogeomorfologia na bacia do Córrego do Cavalheiro - Analândia/SP: Uma avaliação da dinâmica de uso da terra e sua adequabilidade a legislação ambiental e a capacidade de uso. 2011. 102 f. Trabalho de Conclusão de Curso - Instituto de Geociência e Ciências Exatas, Universidade Estadual Paulista, Rio Claro, 2011.

PINTON, L. G. Evolução dos processos morfogenéticos em relevo cuestiforme: a bacia do Córrego do Cavalheiro - Analândia (SP). 2016. 129 f. Tese (Doutorado em Geografia) - Programa de PósGraduação em Geografia, Universidade Estadual Paulista, Rio Claro, 2016.

PRASUHN, V.; LINIGER, H; GISLER, S.; HERWEG, K.; CANDIBAS, A.; CLÉMENT, J. P. A highresolution soil erosion risk map of Switzerland as strategic policy support system. Land Use Policy, v. 32, p. 281-291, 1 maio 2013. DOI.10.1016/j.landusepol.2012.11.006.

QUEIROZ FILHO, A. P.; MARTINELLI, M. Cartografia de análise e de síntese na Geografia. Boletim Paulista de Geografia, n. 87, p. 7-44, 2007.

SAMPAIO, T. V. M. Diretrizes e procedimentos metodológicos para a cartografia de síntese com atributos quantitativos via álgebra de mapas e análise multicritério.Boletim de Geografia, v. 30, n. 1, p. 121-131, 21 jun. 2012.

SANTOS, B. C. DOS, FONTÃO, P. A. B., SOUZA, P. H. de. O efeito do relevo nas chuvas na porção central do Estado de São Paulo em anos padrão extremos. Revista do Departamento de Geografia, n. 40, p. 132-147, 2020. DOI.10.11606/rdg.v40i0.172973.

SARTORI, M. et al. A linkage between the biophysical and the economic: Assessing the global market impacts of soil erosion. Land Use Policy, v. 86, p. 299-312, 1 jul. 2019. DOI.10.1016/j.landusepol.2019.05.014

SCHNEIDER, R. L. et. al. Revisão estratigráfica da Bacia do Paraná. In: CONGRESSO BRASILEIRO GEOLOGIA. 28. 1974, Porto Alegre. Anais... Porto Alegre, 1974, p. 41-65.

SHEN, H.; ZHENG, F.; WEN, L.; HAN, Y.; HU, W. Impacts of rainfall intensity and slope gradient on rill erosion processes at loessial hillslope. Soil and Tillage Research, v. 155, p. 429-436, 2016. DOI.10.1016/j.still.2015.09.011

STEFANUTO, E. B.; ZANATTA, F. A. S.; LUPINACCI, C. M. Análise histórica do uso da terra em Antropogeomorfologia: Alguns exemplos paulistas. Revista Brasileira de Geografia, v.62, n.2, p. 95$112,2017$.

STEFAnUtO, E. B. Análise da Dinâmica Erosiva Linear e seu Potencial Evolutivo em Ambiente Agrícola. 2019. 123 f. Dissertação (Mestrado em Geografia). Programa de Pós-Graduação em Geografia, 
Universidade Estadual Paulista, Rio Claro, 2019.

STOLF, R. Penetrômetro de Impacto Stolf - programa de manipulação de dados em ExcelVBA. UFSCar, 2011. Disponível em: < http://www.cca.ufscar.br/drnpa/hprubismar.htm>. Acesso em: 08 out. 2016.

TENG, H.; ROSSEL, R. A. V.; SHI, Z.; BEHRENS, T.; CHAPPELL, A.; BUI, E. Assimilating satellite imagery and visible-near infrared spectroscopy to model and map soil loss by water erosion in Australia. Environmental Modelling and Software, v. 77, p. 156-167, 1 mar. 2016. DOI.10.1016/j.envsoft.2015.11.024

TROPPMAIR, H. Geossistemas e geossistemas paulistas. Rio Claro: Helmut Troppmair, 2000.

VAZ, C. M. P.; MANIERI, J. M.; MARIA, I. C. de.; TULLER, M. Modeling and correction of soil penetration resistance for varying soil water content. Geoderma. v.166, 92-101, 2011. DOI.10.1016/j.geoderma.2011.07.016

XIA, J.; CAI, C.; WEI, Y.; WU, X. Granite residual soil properties in collapsing gullies of south China: spatial variations and effects on collapsing gully erosion. Catena, v. 174, p. 469-477, 2019. DOI.10.1016/j.catena.2018.11.015

ZAINE, J. E. Geologia da Formação Rio Claro na folha Rio Claro (SP). 1994. 98 f. Dissertação (Mestrado em Geologia Regional) - Instituto de Geociências e Ciências Exatas, Universidade Estadual Paulista, Rio Claro, 1994.

ZANATTA, F. A. S. Limitação Física em área rural degradada: busca metodológica para definir o uso adequado das terras. 2018. 164 f. Tese (Doutorado em Geografia) - Programa de Pós-Graduação em Geografia, Universidade Estadual Paulista, Rio Claro, 2018.

ZHANG, J.; YANG, M.; DENG, X.; LIU, Z.; ZHANG, F. The effects of tillage on sheet erosion on sloping fields in the wind-water erosion crisscross region of the Chinese Loess Plateau. Soil and Tillage Research, v. 187, p. 235-245, 2019. DOI.10.1016/j.still.2018.12.014

\section{Biografia do autor principal}

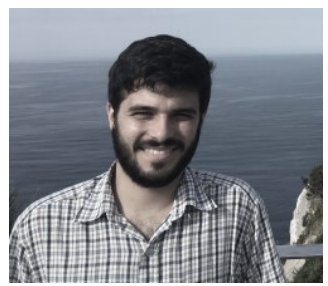

Estêvão Botura Stefanuto nasceu em Bariri (SP) no ano de 1994. É geógrafo (bacharel e licenciado) e mestre em geografia pela Universidade Estadual Paulista - UNESP Campus de Rio Claro. Atualmente é doutorando no Programa de PósGraduação em Geografia da UNESP Campus de Rio Claro. Desenvolve pesquisa em geomorfologia, atuando principalmente na temática erosão de solos. 